\title{
Current concepts of severe asthma
}

\author{
Anuradha Ray, ${ }^{1,2,3}$ Mahesh Raundhal, ${ }^{1}$ Timothy B. Oriss, ${ }^{1}$ Prabir Ray, ${ }^{1,2,3}$ and Sally E. Wenzel ${ }^{1,2,3}$ \\ 'Division of Pulmonary, Allergy, and Critical Care Medicine, Department of Medicine, ${ }^{2}$ Department of Immunology, and ${ }^{3}$ University of Pittsburgh Asthma Institute \\ at University of Pittsburgh Medical Center/University of Pittsburgh School of Medicine, Pittsburgh, Pennsylvania, USA.
}

\begin{abstract}
The term asthma encompasses a disease spectrum with mild to very severe disease phenotypes whose traditional common characteristic is reversible airflow limitation. Unlike milder disease, severe asthma is poorly controlled by the current standard of care. Ongoing studies using advanced molecular and immunological tools along with improved clinical classification show that severe asthma does not identify a specific patient phenotype, but rather includes patients with constant medical needs, whose pathobiologic and clinical characteristics vary widely. Accordingly, in recent clinical trials, therapies guided by specific patient characteristics have had better outcomes than previous therapies directed to any subject with a diagnosis of severe asthma. However, there are still significant gaps in our understanding of the full scope of this disease that hinder the development of effective treatments for all severe asthmatics. In this Review, we discuss our current state of knowledge regarding severe asthma, highlighting different molecular and immunological pathways that can be targeted for future therapeutic development.
\end{abstract}

\section{A brief overview}

Asthma identifies a spectrum of respiratory-related symptoms, typically with a link to reversible airflow limitation. Like the terms arthritis or anemia, the term asthma does not identify any specific underlying pathobiology, but is a broad, umbrella-like term that covers multiple groupings of patient characteristics or phenotypes (1-3). While the term asthma has been traditionally used to describe a childhood onset disease associated with atopic/allergic responses, asthma can develop later in life, with minimal link to allergy. Although mild to severe disease has been identified across the spectrum of asthma, many studies now show that "severe asthma" is not a phenotype, but rather a description of a group of patients with high medical needs, whose pathobiologic and clinical characteristics vary widely $(1,4-8)$. This heterogeneity has made the study of the underlying pathobiologies of severe asthma problematic. Therefore, to move the understanding of severe asthma forward, several factors deserve attention, including (a) a unified clinical definition of the umbrella-term asthma, (b) biased and unbiased approaches for the identification of clinical and (ideally) matched molecular phenotypes, (c) animal models to address the importance of specific molecular pathways, and (d) targeted treatment approaches in humans that confirm the relevance of particular molecular pathways to defined clinical molecular phenotypes. Linking these steps should enable identification of precisely treatable endotypes of severe asthma $(2,7,9)$.

\section{Defining severe asthma and differentiating severe from milder disease}

For the purposes of this review, we will utilize the European Respiratory Society-American Thoracic Society (ERS-ATS) consensus definition of severe asthma. Patients with severe asthma are defined as those patients who require treatment with high-dose

Conflict of interest: The authors have declared that no conflict of interest exists. Reference information: / Clin Invest. 2016;126(7):2394-2403. doi:10.1172/JCI84144. inhaled (or systemic) corticosteroids (CS) in combination with a second long-term (controller) medication. This definition includes patients who either maintain control of their disease or who never achieve control. Lack of asthma control is defined by ongoing frequent or severe symptoms, frequent or severe exacerbations, or evidence of airflow limitation. While this definition does not include any biomarkers to identify severe asthma, it differentiates a group of patients in whom current treatments are either unable to adequately treat the clinical presentation or in whom the risk of side effects from the high doses of the medications is of longterm concern. It is clear that this definition is imperfect. While it is likely that any patient who meets this definition does indeed have severe asthma, it is also likely that many patients who do not fulfill the criteria for use of high-dose CS therapy may also have severe asthma, but are likely undertreated. Most estimates suggest that patients with severe asthma represent $5 \%-10 \%$ of the total asthma population (or $\sim 0.5 \%$ of the overall population of the United States) (10-12). This small percentage still contributes to nearly $50 \%$ of the healthcare costs of asthma $(13,14)$. Using the US CDC estimate for total economic impact, severe asthma carries a cost of approximately $\$ 28$ billion per year. Therefore, severe asthma is a significant economic burden as well as a health burden.

The definition of severe asthma has primarily been based upon CS responsiveness and clinical symptoms; however, the molecular characteristics of the disease have been slow to emerge. Molecular characterization thus far has largely focused on the presence or degree of a type 2 inflammatory response, which involves the prototypical inflammatory cytokines IL-4, IL-5, and IL-13. Studies in both milder and severe asthma consistently show that approximately $50 \%$ of each group manifests a type 2 inflammatory signature $(8,15-17)$; however, in mild asthmatic adults, the presence of a type 2 inflammatory process appears to be linked to early onset, atopic/allergic disease, while in severe asthma, where the presence of atopy is consistently lower, the relationship to atopy/allergy is less clear $(5,18,19)$. Interestingly, cluster analyses of cohorts 
Table 1. Consistently observed clinical/molecular asthma phenotypes

\begin{tabular}{|c|c|c|c|c|c|c|}
\hline Phenotype & Age at onset & Clinical characteristics & Observable type 2 process & Non-type 2 processes & Disease progression & Treatment response \\
\hline $\begin{array}{l}\text { Mild-moderate } \\
\text { allergic asthma }\end{array}$ & $\begin{array}{l}\text { Generally } \\
\text { childhood }\end{array}$ & $\begin{array}{l}\text { Intermittent symptoms } \\
\text { Associated atopy, allergic } \\
\text { rhinitis, seasonal symptoms }\end{array}$ & $\begin{array}{l}\text { Atopic, type } 2 \text { signature } \\
50 \%\end{array}$ & Unknown & Unlikely & $\begin{array}{l}\text { Inhaled CS responsive } \\
\text { in type } 2^{\text {hi }} \text { group } \\
\text { Unknown treatment } \\
\text { in type } 2^{\text {lo }}\end{array}$ \\
\hline $\begin{array}{l}\text { Moderate-severe } \\
\text { allergic asthma }\end{array}$ & $\begin{array}{l}\text { Generally } \\
\text { childhood }\end{array}$ & $\begin{array}{l}\text { Perennial symptoms } \\
\text { Allergic rhinitis } \\
\text { Often obese from long-term } \\
\text { CS use and low activity }\end{array}$ & $\begin{array}{l}\text { IgE, FeNO, and blood } \\
\text { eosinophils elevated but } \\
\text { typically suppressed by CS }\end{array}$ & Likely, but unknown & $\begin{array}{l}\text { Often severe from } \\
\text { childhood or adult } \\
\text { worsening }\end{array}$ & $\begin{array}{l}\text { Inhaled CS responsive } \\
\text { in type } 2^{\text {hi }} \text { group } \\
\text { Often better with addition } \\
\text { of long-acting } \beta \text { agonist } \\
\text { May respond to anti-lgE }\end{array}$ \\
\hline $\begin{array}{l}\text { Eosinophilic asthma } \\
\text { and sinusitis }\end{array}$ & $20 s-40 s$ & $\begin{array}{l}\text { Absence of atopy/allergy } \\
\text { Nasal polyps and severe sinus } \\
\text { disease } \\
\text { Subset with nonsteroidal anti- } \\
\text { inflammatory (aspirin) sensitivity }\end{array}$ & $\begin{array}{l}\text { Very high levels blood } \\
\text { and lung eosinophils } \\
\text { High FeNO }\end{array}$ & $\begin{array}{l}\text { Likely, including } \\
\text { autoimmune }\end{array}$ & $\begin{array}{l}\text { Often severe from } \\
\text { onset }\end{array}$ & $\begin{array}{l}\text { Typically requires } \\
\text { systemic CS } \\
\text { May respond to both } \\
\text { anti-IL-5 and anti-IL-4R }\end{array}$ \\
\hline $\begin{array}{l}\text { Very severe systemic } \\
\text { CS dependent }\end{array}$ & $\begin{array}{l}\text { Adult } \\
\text { worsening } \\
\text { or onset }\end{array}$ & $\begin{array}{l}\text { Perennial severe symptoms } \\
\text { and exacerbation, low levels } \\
\text { of allergy } \\
\text { Often obese from CS use } \\
\text { Family or personal history } \\
\text { of autoimmune disease }\end{array}$ & $\begin{array}{l}\text { Persistent type } 2 \text { process } \\
\text { despite CS } \\
\text { FeNO persistently } \\
\text { elevated, blood and } \\
\text { lung eosinophils } \\
\text { lgE often low }\end{array}$ & Type 1, possibly type 17 & $\begin{array}{l}\text { Severe from time of } \\
\text { onset or "2nd hit" }\end{array}$ & $\begin{array}{l}\text { Systemic corticosteroids } \\
\text { Anti-IL-5 } \\
\text { May respond to } \\
\text { azathioprine, } \\
\text { mycophenolate }\end{array}$ \\
\hline $\begin{array}{l}\text { Obese late-onset } \\
\text { asthma }\end{array}$ & $\begin{array}{l}\text { Teenage to } \\
\text { adulthood }\end{array}$ & $\begin{array}{l}\text { Obesity } \\
\text { Gastroesophageal reflux }\end{array}$ & Low to none & $\begin{array}{l}\text { Metabolic processes } \\
\text { including oxidative } \\
\text { stress, elevated IL-6 }\end{array}$ & $\begin{array}{l}\text { May worsen with } \\
\text { weight gain/ } \\
\text { overuse of CS }\end{array}$ & $\begin{array}{l}\text { Weight loss/ } \\
\text { bariatric surgery }\end{array}$ \\
\hline
\end{tabular}

that included both severe and milder asthma patients showed that milder asthma tends to be present in smaller numbers of clusters, generally as early onset and allergic disease, half of which has a CS-responsive type 2 inflammatory component $(6,8,17,20)$. Table 1 summarizes our current understanding of asthma phenotypes along with response to different therapies. While a large European cluster analysis suggested that this mild, allergic phenotype was stable over time, little longitudinal data are available to assess the stability of clinical or molecular phenotypes over time (21).

\section{Severe asthma phenotypes encompass more than a type 2 inflammatory signature}

Given the understanding that asthma and severe asthma are heterogeneous conditions, numerous biased and unbiased studies have been undertaken across European (European Network for the Understanding and Management of Severe Asthma [ENFUMOSA], Unbiased Biomarkers for the Prediction of Respiratory Disease Outcomes [U-BIOPRED]) and American ([Severe Asthma Research Program [SARP]) networks to identify clinical and molecular phenotypes of severe asthma. Despite the various approaches to identifying severe asthma phenotypes, consistently reproducible subgroups are emerging.

Recent unbiased and biased approaches have consistently shown the importance of age at onset to severe asthma phenotypes $(6,8,20,22)$. Early age at onset better identifies "allergic asthma" than clinically available tests of atopy/allergy, whereas later onset asthma identifies a mixed population of patients, many of whom appear to be identified either by nasal polyps/ sinus disease and eosinophilia or by a female, obese phenotype with less airflow limitation $(6,8,20)$. Intriguingly, despite the decreasing prevalence of atopy in severe disease, studies of various type 2 inflammation-directed therapies are beginning to link the adult onset/nasal polyp-associated phenotype with type 2 cytokine pathways, including pathways traditionally associated with atopy/allergy (IL-4 and IL-13) and eosinophils (IL-5) (6, $8,20)$. Whether these clinical responses in less allergic/atopic patients imply efficacy disassociated from allergy or whether IgE responses exist locally or to nontraditional allergens is not known. It is important to note in this context that antigens other than those present in agents classified as allergens may promote a high IgE response in some severe asthma subjects. For example, bacterial superantigens have been implicated in $\mathrm{T}$ cell responses in the airways of subjects with poorly controlled asthma (23). It is well recognized that most patients with atopic dermatitis harbor specific antibodies against superantigens in Staphylococcus aureus (24). IgE antibodies to Staphylococcal enterotoxins were identified in nasal polyp tissue and associated with local polyclonal IgE production and eosinophilic inflammation (25), and serum Staphylococcus antigen-specific IgE levels were found to correlate with asthma severity (26).

That type 2 cytokines can be expressed in the airways of both atopic and nonatopic asthmatics was noted in the mid-1990s (27). Recent studies consistently identify a group of patients with the most severe form of asthma in whom a complex inflammatory process is present despite use of high doses of inhaled and often systemic CS. Using 112 variables, including immune-inflamma- 


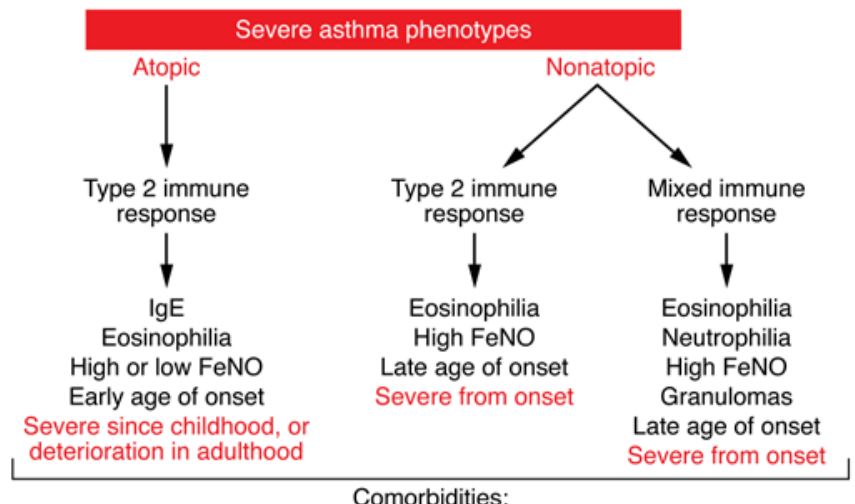

rhinitis/nasal polyps, sinusitis, infections, obesity, female, smoking
Figure 1. Severe asthma phenotypes based on clinical, molecular, and immunological characteristics. Disease onset at early age is usually associated with atopy, but type 2 inflammation is suppressed in only a subset of patients. Disease with late-age onset is highly heterogeneous in nature, as shown. The type 2 inflammatory response is undetectable in the airways of many of these subjects with low serum IgE, and this phenotype is associated with comorbidities such as obesity and smoking. Type 2 immune response with variable IgE, eosinophilia, and high FeNO is also a feature of late-onset disease with nasal polyps, which are detected in many of these subjects. Another patient subset includes extremely sick subjects with mixed granulocytic response, variable FeNO, and granulomas in their airways, suggesting autoimmune responses. tory cell counts from blood and bronchoalveolar lavage fluid (BALF), allergy skin tests, and IgE, Wu and colleagues identified a severe asthma cluster in the SARP cohort in which nearly $100 \%$ of patients had three or more systemic CS bursts in the previous year, with many of these patients already receiving systemic CS (8). These severe patients were characterized by the lowest lung function in the cohort and persistent BALF eosinophilia in combination with high levels of neutrophils and exhaled nitric oxide (FeNO). Persistent FeNO elevation in the most severe asthma cluster was unexpected, given the known effect of CS to decrease FeNO levels in milder asthma, but this finding was consistent with a previous report that identified FeNO as the most important independent factor associated with chronic systemic CS use in patients with severe asthma $(28,29)$. The enzyme that generates NO [inducible NOS (iNOS)] is strongly associated with type 2/ IL-13-induced inflammation (30). Expression of iNOS is reduced by approximately $50 \%$ in response to IL-4/IL-13-directed therapy, even in patients already on moderate to high doses of inhaled CS (31-34). Importantly, iNOS is also induced in human airway epithelial cells by other cytokines, particularly IFN- $\gamma$ (35). To further address the complex role of FeNO in underlying molecular processes of asthma and severe asthma in particular, an epithelial cell gene-profiling study to identify genes strongly correlated with FeNO level was performed on asthmatics with a range of endotypes and healthy controls (16). The resulting 589 correlated genes were then used to cluster 155 patients. Five different clusters emerged from this analysis (16). Three of these clusters had high FeNO; two of these were associated with greater disease diversity (16). The remaining two clusters had low FeNO; one of these was associated with more severe disease (16). In addition to elevation of type 2-related genes, one of the three high FeNO clusters also exhibited elevations of IFN-related genes. Thus, unbiased molecular approaches also suggest that non-type 2 inflammation (in the presence or absence of persistent type 2 inflammation) is likely to be important in some patients with severe disease.

Additional support for the role of non-type 2 inflammatory processes was provided by a study in which a group of patients with long-term CS dependency and persistent elevations in FeNO and blood eosinophils underwent video-assisted thoracoscopic biopsies of the distal lung. These patients had persistent eosinophilic small airway inflammation and, surprisingly, poorly formed nonnecrotizing granulomas in the absence of vasculitis
(36). The presence of granulomas further supports the presence of non-type 2 immunity. Figure 1 depicts the classification of severe asthma into different phenotypes based on age of onset, atopy, and other parameters determined by clinical, immunological, and molecular assessments. Unfortunately, the natural history of all of these phenotypes is poorly understood. In many patients, severe asthma appears to be severe from its initiation, whether in childhood or in adulthood, while in other cases a "second hit" may occur, such as a viral infection or hormonal change, which may change a mild asthma presentation to one that is much more severe. Interestingly, long-term progression from mild to severe asthma may be less common. Thus, asthma, and severe asthma in particular, appears to demonstrate a persistent type 2 immune process that in many cases involves cells of both the innate and adaptive immune systems, often in association with other immune pathways. The following section will specifically discuss this topic including a central role of the transcription factor GATA3 in type 2 immunity in general.

\section{Type 2 inflammation and GATA3 in asthma}

The Th1/Th2 paradigm was established in the mid-1980s based on studies of the immune system in mice (37). In the early 1990s, the presence of type 2 cytokines was reported in the airways of asthmatics (38-40). Thereafter, an increasing appreciation of Th1 or Th2 cytokine signatures in different human diseases spurred research to define the molecular basis for Th1 versus Th2 development. The transcription factor GATA3 was shown to be selectively expressed in Th2 cells $(41,42)$, and inhibition of GATA3 activity in experimental allergic asthma blunted development of allergic airway inflammation (43). Importantly, increased GATA3 expression was observed in the airways of asthmatics (44). Further research using $\mathrm{CD}^{+} \mathrm{T}$ cell-specific conditional knockout mice showed that GATA3 is critical for the expression of all of the Th2-specific cytokines (IL-4, IL-5, and IL-13) (45), establishing GATA3 as an attractive target in the treatment of asthma associated with Th2 responses. In a recent study, when mild allergic asthmatics subjected to allergen provocation were treated with a GATA3-specific DNAzyme, both early and late asthmatic responses were significantly attenuated $(46,47)$. More studies are needed to determine whether inhibition of GATA3 activity can control other clinical features of mild asthma in the absence of allergen challenge. Because type 2 cytokines remain elevated in the airways of some 
Table 2. Available and emerging type 2 response-targeted therapies for asthma

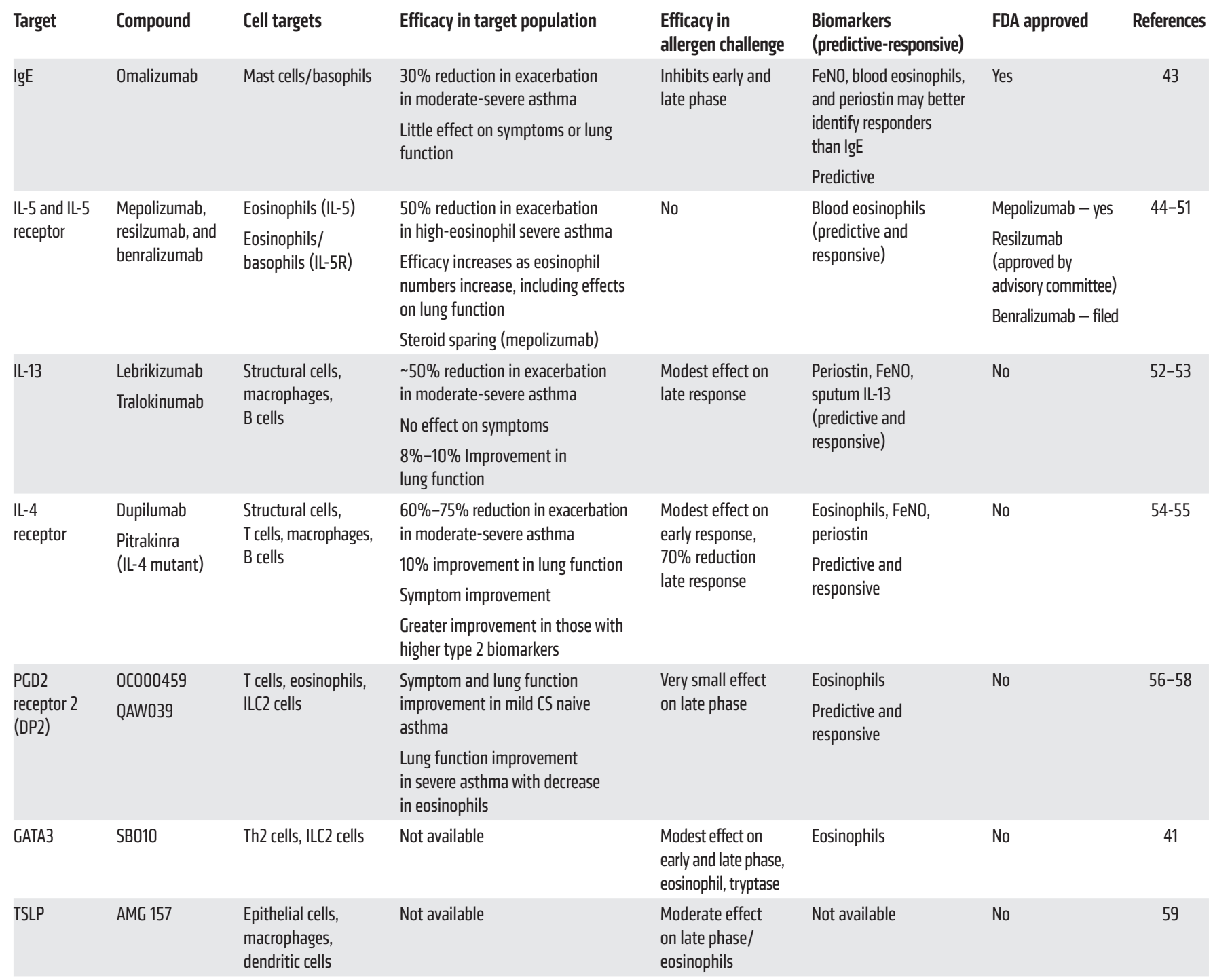

severe asthma patients despite high-dose CS therapy (48), targeting GATA3 may achieve at least some degree of disease control in this group of asthmatics.

Because severe asthma patients exhibit poor responses to $\mathrm{CS}$, the underlying mechanisms or their disease endotypes are likely to be different than in patients with more mild forms of the disease. Similarly, there is heterogeneity in disease characteristics and manifestations in severe asthma that may differentially influence poor CS responsiveness. Clustering analyses of severe asthma based on different variables show segregation into different subclasses $(6,8,16)$. Many of these clusters are associated with high eosinophilia, and type 2 cytokine-directed therapies in specific subgroups have shown promise (Table 2) (32-34, 47, 49-62). In multiple studies, anti-IL-5 or anti-IL-5R therapy in patients with blood or sputum eosinophilia resulted in decreased exacerbations, lower daily oral CS dose, and, in some instances, improved symptoms and lung function $(51,53,55,57,63)$, con- sistent with active involvement of type 2 pathways downstream from GATA3 (41, 42, 45). Additionally, antibodies targeting IL-4 and/or IL-13 also consistently show efficacy in severe asthma, with the best efficacy seen in patients with more biomarker evidence for type 2 inflammation (elevations in blood/sputum eosinophils, FeNO, or IL-13-induced periostin). In patients with modestly elevated levels of blood eosinophils, treatment with the anti-IL-4R $\alpha$ antibody dupilumab maintained and even improved asthma control in moderate to severe asthma when background bronchodilator and CS therapy were withdrawn (33). Dupilumab treatment also improved asthma symptoms in combination with inhaled CS, supportive of the presence of residual, CS-refractory type 2 inflammation (33). Further, FeNO levels were cut nearly in half, supporting the biologic impact on type 2 inflammation (33). Similarly, dupilumab treatment reduced nasal polyp burden and improved quality of life in subjects who were refractory to CS treatment (64). Taken together, these observations further 
suggest common underlying mechanisms in CS-refractory nasal polyps and severe asthma. The possibility of crosstalk between these two sites is discussed later in this Review. In the case of IL-13-directed therapy, while the IL-13 antibody lebrikizumab was only modestly efficacious in the total patient cohort, it markedly improved forced expiratory volume in 1 second (FEV1) in patients with high-serum periostin levels, a biomarker for type 2 inflammation (32). Thus, substantial evidence now supports the presence of ongoing type 2 inflammation in moderate to severe asthma (even in the presence of CS therapy), which can be successfully targeted to improve outcome.

Given that GATA3 is crucial for the expression of all type 2 cytokines $(41,42,45)$, it is reasonable to predict that targeting GATA3 will be effective in the treatment of severe asthma associated with high eosinophilia or FeNO. It appears that while moderate to high doses of CS are not effective in controlling severe asthma, as discussed above, IL-4-, IL-13-, or IL-5-directed therapy in targeted patient cohorts has shown promise in multiple independent studies. These studies suggest a general defect in the function of the glucocorticoid receptor (GR), resulting in persistent, residual CS-refractory type 2 inflammation (48). This CS unresponsiveness is not generally seen in mild allergic asthma, at least in the presence of type 2 inflammation. It is plausible that type 2 cytokines in severe asthma synergize with other cytokines and/or mediators to affect various target cells, including mast cells, eosinophils, epithelial cells, and airway smooth muscle cells, resulting in poor lung function and promotion of asthma exacerbations.

\section{A role for innate type 2 immunity}

In order to evaluate the immune response in severe asthma, it is important to consider the cellular sources of the type 2 cytokines. Cells of the innate immune system, such as NKT cells, alternatively activated macrophages, eosinophils, and mast cells, can produce type 2 cytokines, although more studies are needed to identify conditions that can trigger human macrophages to secrete type 2 cytokines (65). Type 2 innate lymphoid cells (ILC2s) also produce significant amounts of the type 2 cytokines IL- 5 and IL-13 $(66,67)$, and cytokine production is regulated by GATA3 $(68,69)$. Studies in both mice and humans show that these cells produce large amounts of IL-5 and IL-13 in the presence of the epithelial cell-derived cytokines thymic stromal lymphopoietin (TSLP), IL-25, IL-33 (70), and prostaglandin D2 (PGD2) $(71,72)$. The release of these cytokines is induced by proteases, which are present in various allergens (73), as well as viruses, including rhinovirus, and bacteria, such as staphylococcus, which have been associated with asthma exacerbations and chronic sinusitis (74, 75). Since approximately $25 \%$ of patients with severe asthma do not display atopy (at least to known allergens), it is possible that there are other environmental triggers that induce a type 2 response without invoking a Th2 response.

Many allergen, such as house dust mite (HDM), cockroach, fungal allergens (Alternaria), and some pollens, among other allergens, harbor protease activity $(70,73,76)$. In mouse studies, some of these proteases were found to cause an increase in IL-33 and IL-25 levels in the airways $(70,73,76)$. Additionally, mast cell- and neutrophil-derived proteases cause processing of IL-1 family proteins (IL-33 being a member of this class), resulting in release of truncated cytokines with enhanced biological activities, although the exact cellular source of these cytokines in severe asthma is currently unclear (77). It is interesting to consider the possibility that in some patients, allergens and other environmental agents with protease activity induce low or no type 2 sensitization that would result in Th2 skewing and increased IgE levels, but instead promote the production of TSLP, IL-25, IL-33, or PGD2, which induce type 2 cytokine production in ILC2s. In a study of human subjects infected with rhinovirus, an increase in the level of IL-33 was detected in BALF (78). In this same study, supernatants of rhinovirus-infected airway epithelial cells increased the secretion of IL- 5 and IL-13 by both cultured T cells and ILC2s; however, ILC2s secreted 40-fold more IL-5 and 10-fold more IL-13 than T cells, even though the number of ILC2s was one-tenth that of T cells (78). Despite the fact that ILC2s are not numerous (largely based on mouse studies), these cells are able to secrete a large amount of cytokine and are not restricted by antigen specificity as are T cells; thus, it is easy to appreciate the potential of ILC2s to promote disease if they are stimulated by cytokines such as IL-33. Recent studies have failed to detect increased epithelial IL-33 in bronchial biopsies from adults or children with asthma; however, increased IL-33 expression was observed in submucosal inflammatory cells in children with severe asthma (79). An important area of future investigations is the identification of triggers that cause the release of bioactive ILC2-inducing factors in the airways of human subjects as well as the source of these factors.

Two recent studies have reported the presence of ILC2s in the airways of severe asthmatics $(80,81)$. While the results are intriguing, the relatively small number of individuals examined highlights the need for additional studies to unequivocally demonstrate that severe asthmatics harbor greater numbers of activated ILC2s in their airways as compared with their milder counterparts or healthy controls. However, the technical hurdles associated with identifying and characterizing these infrequent cells in the airways are considerable. It is also possible that the airways are not always the primary site of an inflammatory immune response. Instead, crosstalk between the nasal mucosa and the airways occurs in severe asthma via systemic effects due to leakage of cytokines such as IL-5 from the local site (nose) of inflammation $(82,83)$. As reported in an eight-year-long study of atopic and nonatopic asthmatics, adults were more likely to develop asthma if they had rhinitis at baseline (82). The nasal mucosa may be the primary site of a heightened type 2 response involving ILC2s. The release of IL- 5 from activated ILC2s may result in a systemic increase in the levels of IL-5 and chemokines, which triggers a response in the bone marrow that results in increased eosinophil proliferation and differentiation with release into circulation followed by recruitment to the airways $(84,85)$. If ILC2s are indeed culprits in severe asthma, then the cell-surface receptors that respond to upstream trigger cytokines or the type 2 cytokines themselves could serve as therapeutic targets. Additionally, it will be interesting to study the effect of GATA3 blockade-mediated suppression of type 2 effector cytokines on ILC2s.

\section{The role of IFN- $\boldsymbol{\gamma}$ in severe asthma}

Even if ILC2s and not Th2 cells are involved in the pathogenesis of nonallergic (and potentially allergic) severe asthma, it is unclear 
why this class of asthma is insensitive to CS therapy. If type 2 cytokine effector function is suppressed by CS in mild asthma, why does this fail in severe asthma? One logical explanation is that, in addition to type 2 cytokines, there are other mediators in severe asthma, as suggested by clustering studies $(8,16)$ and the identification of granulomas (36) and neutrophils in some subjects $(4,48$, 86-88). Indeed, when cells present in the BALF of subjects with mild to moderate or severe asthma were analyzed, a higher level of IFNG mRNA was detected in the airways of severe asthmatics (48). Characterization of the immune cells recovered in BALF revealed a higher Th1 profile in more than $50 \%$ of severe asthmatics as compared to that in the milder subjects, as evidenced by the frequency of IFN $-\gamma^{+} \mathrm{CD} 4^{+}$T cells and the amount of secreted IFN- $\gamma$ (48). Earlier studies of different asthma cohorts have also noted increased expression of IFNG mRNA in the lung tissue and sputum of subjects with severe asthma $(89,90)$. In a GWAS, genetic scores of SNPs in four genes in the Th1 pathway, IL12A, IL12RB1, $S T A T 4$, and IRF2, were cumulatively, inversely associated with the predicted percentage of FEV1 and were positively associated with asthma severity (91). As revealed by cluster analysis, patients with the most severe disease have high levels of CS-unresponsive FeNO (16) and iNOS, which is induced by IFN- $\gamma$ as well as type 2 cytokines. These findings suggest that many features of severe asthma, including persistently high levels of airway eosinophils (sometimes accompanied by neutrophils) and FeNO, may be due to elements of persistent, CS-refractory type 2 inflammation and/ or additional inflammatory processes.

\section{Infection, IFN- $\gamma$, and severe asthma}

The finding of high levels of IFN- $\gamma$ in the airways of severe asthmatics raises the question of the trigger for the IFN- $\gamma$ response. The most common inducer of an IFN- $\gamma$ response is infection (92). Persistent infections by viruses (rhinovirus being the most common) and bacteria have been noted in severe asthma, and infections are associated with asthma exacerbations (92). Bacterial species associated with severe disease include Chlamydia pneumoniae, Streptococcus pneumoniae, Mycoplasma pneumoniae, Haemophilus influenzae, Moraxella catarrhalis, and S. aureus. As discussed above, Staphylococcal superantigen-specific serum IgE antibodies correlate with disease severity (26). Taken together, the results of independent studies suggest causality between chronic infections and severe asthma (92).

The bacteria detected in the context of asthma exacerbations can generate the intracellular messenger cyclic-di-GMP (c-diGMP) (93), which induces type I IFNs via the stimulator of interferon genes (STING) pathway (94). Type I IFNs are also induced in defense against virus infections. c-di-GMP can function as an adjuvant for the induction of Th1 and Th17 immune responses mixed with a low Th2 immune response (95). Given these attributes of c-di-GMP, we recently used a combination of the allergen HDM and c-di-GMP to induce a mixed Th1 and Th17 immune response along with a low Th2 response in the airways of mice that were detectable even in the presence of a high dose of CS, mimicking the CS-refractory immune response in severe asthmatics (48). When WT, Ifng ${ }^{-/}$, and Il17 $\mathrm{ra}^{-/-}$mice were subjected to this model of asthma, the increased methacholine-induced airway hyperresponsiveness (AHR, a hallmark of asthma) in the WT mice, which was only partially responsive to CS, was completely attenuated in

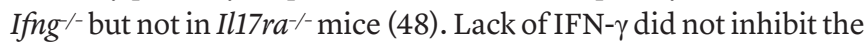
inflammatory response in murine airways, although IL-17 signaling deficiency markedly suppressed the neutrophil influx into the airways (48). Previous studies of mouse models of asthma have also associated IFN- $\gamma$ with $\operatorname{AHR}(96,97)$, and IFN- $\gamma$-induced AHR is poorly responsive to CS (97). While IL-17 promotes neutrophil recruitment into the airways in humans and mice (98-101), neutrophilic inflammation may not be the cause of poor lung function, although neutrophil-derived products such as neutrophil elastase may promote tissue destruction. As opposed to favorable results with anti-type 2 cytokine therapy, targeting IL-17 has failed to improve disease symptoms in severe asthma patients (102). Recent studies have identified an interesting dichotomy in Th17 cells with the existence of two subtypes: pathogenic and nonpathogenic (103-105). It is possible that the Th17 cells in severe asthma are nonpathogenic in nature; thus, targeting them does not improve disease outcomes. However, additional studies are needed to determine the role of Th17 cells in severe asthma.

\section{Downstream effects of IFN- $\gamma$ influencing the severe asthma phenotype}

In efforts to determine how IFN- $\gamma$ induces AHR, computer-assisted gene analysis identified secretory leukocyte protease inhibitor (SLPI) (106) as a link between IFN- $\gamma$ and AHR (48). SLPI expression was lower in the airways of WT mice compared with Ifng/- mice subjected to the severe asthma model (48). Similarly, paired analysis of BALF cell expression of IFN- $\gamma$ and SLPI in the airway cells of severe asthmatics showed a significant inverse relationship (48).

SLPI can be detected in various body fluids, including nasal and bronchial mucosal secretions (106). In mice, SLPI was found to be expressed in macrophages rendered hyporesponsive to LPS, which was reversed by IFN- $\gamma$ (107). Additionally, overexpression of SLPI in macrophages inhibited NO production (107). In humans, airway epithelial cells rather than alveolar macrophages express iNOS, and low levels of SLPI expression in these cells in severe asthmatics may contribute to increased FeNO production. The elevated levels of FeNO in severe asthmatics requiring a high dose of CS may be due to IFN- $\gamma$-mediated suppression of SLPI in the airway cells (8).

SLPI is a potent inhibitor of multiple leukocyte serine proteases, including mast cell-produced chymase and tryptase as well as neutrophil elastase. Tryptase was shown to promote AHR by activating protease-activated receptor 2 (PAR2), which can promote AHR through release of neurokinins from afferent neurons in the bronchial tissue (108). Additionally, human mast cell-derived tryptase can degrade bronchodilating neuropeptides (109). A mast cell-dependent role for IFN- $\gamma$ in airway remodeling, AHR, and airway inflammation was demonstrated in an ovalbumin-based model of chronic asthma (110). It is possible that in this chronic model the underlying mechanism of increased AHR is an IFN- $\gamma$-mediated decrease in SLPI expression in airway epithelial cells. In a study of wound healing in skin, Slpi-deficient mice were found to generate active TGF- $\beta$, which played a role in wound healing (111). Given the well-established role of TGF- $\beta$ in airway remodeling (112), SLPI deficiency may play a major role in airway remodeling in asthma, which is believed to be responsible for persistent AHR (113). As discussed above, mast cell and neutrophil proteases can cause 


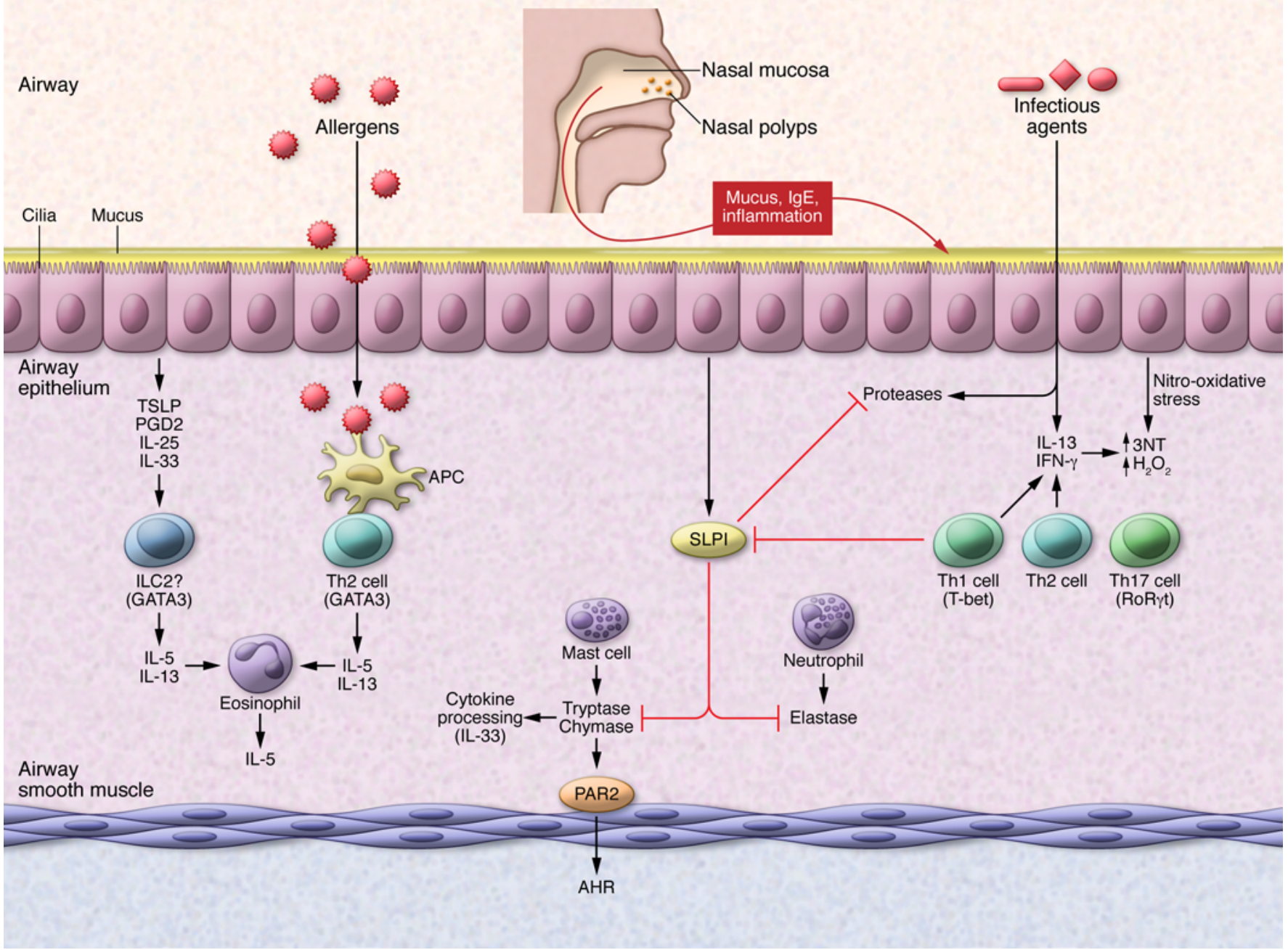

Figure 2. Environmental influence on severe asthma and a complex relationship among the immune system, airway epithelial cells, and airway smooth muscle cells in the airways of severe asthmatics. Allergens and/or other environmental agents with or without protease activity and different pathogens may elicit severe disease early or late in life. Therapies directed against various arms of the type 2 immune response based on the patient's inflammatory response and other characteristics have shown promise in recent clinical trials. While an IFN- $\gamma$ (Th1/type 1 ) immune response has been identified in different patient cohorts, no therapy has yet been directed against this arm of the immune response. IFN- $\gamma$ can inhibit SLPI expression from airway epithelial cells. SLPI is a protease inhibitor secreted by airway epithelial cells that inhibits proteases present in different cell types (mast cells, neutrophils) and infectious agents. Protease-activated PAR2 on airway smooth muscle cells has been implicated in AHR in animal studies. IFN- $\gamma$ and low levels of the type 2 cytokine IL-13 can synergize to induce nitro-oxidative stress in airway epithelial cells. Future studies will determine the potential role of ILC2s and of ILC2-activating cytokines such as IL-33 in severe asthma. Nasal polyps are also encountered in severe asthma, usually in late-onset disease, and crosstalk between the nasal mucosa and the airways may occur due to leakage of cytokines such as IL-5 from the local site (nose) of inflammation. APC, antigen-presenting cell.

proteolytic activation of IL-33, which significantly augments the potency of IL-33. Thus, it is possible that SLPI plays a fundamental role in inhibiting both allergen- and cell-associated proteases such that SLPI downregulation promotes a severe asthma phenotype via effects on AHR, FeNO levels, and airway remodeling.

IFN- $\gamma$ also synergizes with type 2 cytokines such as IL-13 to promote nitro-oxidative stress in airway epithelial cells (114). IL-13 and IFN- $\gamma$ synergistically enhanced iNOS activation and production of nitrite and 3 nitro-tyrosine (3NT) in epithelial cells, which correlated with increased $\mathrm{H}_{2} \mathrm{O}_{2}$ production (114). This in vitro effect on oxidative stress in the epithelial cells closely corresponded to high levels of 3NT and IFNG mRNA in the lungs of severe asthma subjects (114). Figure 2 illustrates our current understanding of altered immune responses in the nasal tissue and airways that underlie severe asthma. Variations of these immune pathways can be detected in different patients, allowing classification into different phenotypes, as shown in Figure 1.

IFN- $\gamma$ induces activation of STAT1 in target cells. Increased nuclear staining of STAT1 was previously noted in airway epithelial cells of asthmatics (115). Although these subjects were not identified as severe asthmatics, since a low level of IFN- $\gamma$ is also detectable in the airways of subjects with mild asthma, it is possible that the duration of STAT1 activation in severe asthma is longer compared with that in mild asthma because of the host's 
response to persistent infection. Both type I and type II IFNs (IFN$\alpha / \beta$ and IFN $-\gamma$, respectively) play an important role in defense against pathogens, and STAT1 is the critical molecule downstream of both IFNs either in the form of a hetero- or homodimer (116). Thus, crippling STAT1 may relieve disease symptoms, but may also interfere with pathogen clearance. It will be interesting to see whether promotion of STAT1 activation to optimal levels (117) will benefit asthmatics with evidence of chronic infection.

\section{Combination therapy in severe asthma}

Severe asthmatics usually need a combination of therapies to achieve asthma control and minimize exacerbations. These treatments typically utilize high-dose CS in combination with a long-acting $\beta_{2}$-adrenergic receptor agonist along with additional adjunctive treatments, such as those directed against IgE (118). However, clearly, for currently poorly understood reasons, disease symptoms and asthma exacerbations in patients with very severe disease are not adequately managed despite use of these combined therapies. With our current knowledge of the complex nature of the immune response in many of these individuals along with a possible role of infectious agents contributing to disease phenotype, newer approaches are necessary to manage severe asthma. A strategy to clear infectious agents with simultaneous suppression of type 2 immune responses, which may be achieved by targeting GATA3, along with restoration of SLPI levels, may control disease symptoms in many severe asthmatics. Regardless, these combination therapies need to be guided by the molecular phenotype of asthma in each individual.

\section{Molecular phenotyping of asthma for better patient care?}

Recent publications illustrate the importance of identifying the right patient cohort for each therapeutic approach and regimen.
Type 2-directed therapies in biomarker-defined populations are now showing profound efficacy in patients with severe asthma who are poorly responsive to CS. However, it is unclear whether these treatments will be effective in all patients with our current set of limited type 2 biomarkers or whether patients without these biomarkers may still respond, perhaps due to CS treatment lowering the biomarker levels, but leaving some residual type $2 \mathrm{immu}-$ nity. Ancillary studies of type 2-targeted therapies to define better biomarkers are clearly needed to further guide the use of these therapies. While a Th1 response has been associated with severe asthma in different studies (48, 89-91, 114), more investigations are necessary using larger patient cohorts for a better understanding of the prevalence of this response and to also determine whether this response is related to specific patient demographics. The influence of comorbidities on severe asthma pathogenesis also needs to be better understood for therapeutic guidance. Future clinical trials of CS-refractory severe asthma will need to be tailored to the specific immune aberration in each subject. The combination of clinical and molecular phenotyping of asthma is therefore critical for the success of therapy.

\section{Acknowledgments}

This work was supported by NIH grants AI106684 (to A. Ray and S.E. Wenzel); HL113956 (to A. Ray and P. Ray); AI048927 (to A. Ray); HL109086, HL69174, AI40600 (to S.E. Wenzel); and AI100012 (to P. Ray).

Address correspondence to: Anuradha Ray or Sally E. Wenzel, Department of Medicine, Pulmonary, Allergy and Critical Care Medicine, University of Pittsburgh School of Medicine, 3459 Fifth Avenue, MUH A628 NW, Pittsburgh, Pennsylvania 15213, USA. Phone: 412.802.3191; E-mail: raya@pitt.edu (A. Ray); Phone: 412.802.6859; E-mail: wenzelse@upmc.edu (S.E. Wenzel).
1. Wenzel S. Asthma phenotypes: the evolution from clinical to molecular approaches. Nat Med. 2012;18(5):716-725.

2. Gauthier M, Ray A, Wenzel SE. Evolving concepts of asthma. Am J Respir Crit Care Med. 2015;192(6):660-668.

3. Ray A, Oriss TB, Wenzel SE. Emerging molecular phenotypes of asthma. Am J Physiol Lung Cell Mol Physiol. 2015;308(2):L130-L140.

4. Wenzel SE. Asthma: defining of the persistent adult phenotypes. Lancet. 2006;368(9537):804-813.

5. Moore WC, et al. Characterization of the severe asthma phenotype by the National Heart, Lung, and Blood Institute's Severe Asthma Research Program. JAllergy Clin Immunol. 2007;119(2):405-413.

6. Moore WC, et al. Identification of asthma phenotypes using cluster analysis in the Severe Asthma Research Program. Am J Respir Crit Care Med. 2010;181(4):315-323.

7. Lötvall J, et al. Asthma endotypes: a new approach to classification of disease entities within the asthma syndrome. J Allergy Clin Immunol. 2011;127(2):355-360.

8. Wu W, et al. Unsupervised phenotyping of Severe Asthma Research Program participants using expanded lung data. J Allergy Clin Immunol. 2014;133(5):1280-1288.

9. Anderson GP. Endotyping asthma: new insights into key pathogenic mechanisms in a complex, heterogeneous disease. Lancet. 2008;372(9643):1107-1119.

10. Slejko JF, et al. Asthma control in the United States, 2008-2010: indicators of poor asthma control. J Allergy Clin Immunol. 2014;133(6):1579-1587.

11. Chung KF, et al. International ERS/ATS guidelines on definition, evaluation and treatment of severe asthma. Eur Respir J. 2014;43(2):343-373.

12. Fleming L, et al. The burden of severe asthma in childhood and adolescence: results from the paediatric U-BIOPRED cohorts. Eur Respir J. 2015;46(5):1322-1333.

13. Fitzpatrick AM, Baena-Cagnani CE, Bacharier LB. Severe asthma in childhood: recent advances in phenotyping and pathogenesis. Curr Opin Allergy Clin Immunol. 2012;12(2):193-201.

14. Sullivan SD, Rasouliyan L, Russo PA, Kamath T, Chipps BE, TENOR Study Group. Extent, patterns, and burden of uncontrolled disease in severe or difficult-to-treat asthma. Allergy. 2007;62(2):126-133.

15. Fajt ML, et al. Prostaglandin $\mathrm{D}_{2}$ pathway upregu- lation: relation to asthma severity, control, and TH2 inflammation. J Allergy Clin Immunol. 2013;131(6):1504-1512.

16. Modena BD, et al. Gene expression in relation to exhaled nitric oxide identifies novel asthma phenotypes with unique biomolecular pathways. Am J Respir Crit Care Med. 2014;190(12):1363-1372.

17. Woodruff PG, et al. T-helper type 2-driven inflammation defines major subphenotypes of asthma. Am J Respir Crit Care Med. 2009;180(5):388-395.

18. [No authors listed]. The ENFUMOSA cross-sectional European multicentre study of the clinical phenotype of chronic severe asthma. European Network for Understanding Mechanisms of Severe Asthma. Eur Respir J. 2003;22(3):470-477.

19. Shaw DE, et al. Clinical and inflammatory characteristics of the European U-BIOPRED adult severe asthma cohort. Eur Respir J. 2015;46(5):1308-1321.

20. Haldar P, et al. Cluster analysis and clinical asthma phenotypes. Am J Respir Crit Care Med. 2008;178(3):218-224.

21. Boudier A, et al. Ten-year follow-up of clusterbased asthma phenotypes in adults. A pooled analysis of three cohorts. Am J Respir Crit Care 
Med. 2013;188(5):550-560.

22. Miranda C, Busacker A, Balzar S, Trudeau J, Wenzel SE. Distinguishing severe asthma phenotypes: role of age at onset and eosinophilic inflammation. J Allergy Clin Immunol. 2004;113(1):101-108.

23. Hauk PJ, Wenzel SE, Trumble AE, Szefler SJ, Leung DY. Increased T-cell receptor vbeta8+ T cells in bronchoalveolar lavage fluid of subjects with poorly controlled asthma: a potential role for microbial superantigens. J Allergy Clin Immunol. 1999;104(1):37-45.

24. Leung DY, et al. Presence of IgE antibodies to staphylococcal exotoxins on the skin of patients with atopic dermatitis. Evidence for a new group of allergens. J Clin Invest. 1993;92(3):1374-1380.

25. Bachert C, Gevaert P, Holtappels G, Johansson SG, van Cauwenberge P. Total and specific $\mathrm{IgE}$ in nasal polyps is related to local eosinophilic inflammation. J Allergy Clin Immunol. 2001;107(4):607-614.

26. Bachert C, Gevaert P, Howarth P, Holtappels $G$, van Cauwenberge P, Johansson SG. IgE to Staphylococcus aureus enterotoxins in serum is related to severity of asthma. J Allergy Clin Immunol. 2003;111(5):1131-1132.

27. Humbert M, et al. IL-4 and IL-5 mRNA and protein in bronchial biopsies from patients with atopic and nonatopic asthma: evidence against "intrinsic" asthma being a distinct immunopathologic entity. Am J Respir Crit Care Med. 1996;154(5):1497-1504.

28. Stirling RG, et al. Increase in exhaled nitric oxide levels in patients with difficult asthma and correlation with symptoms and disease severity despite treatment with oral and inhaled corticosteroids. Asthma and Allergy Group. Thorax. 1998;53(12):1030-1034.

29. Wysocki K, et al. Characterization of factors associated with systemic corticosteroid use in severe asthma: data from the Severe Asthma Research Program. JAllergy Clin Immunol. 2014;133(3):915-918.

30. Muijsers RB, ten Hacken NH, Van Ark I, Folkerts G, Nijkamp FP, Postma DS. L-Arginine is not the limiting factor for nitric oxide synthesis by human alveolar macrophages in vitro. Eur Respir J. 2001;18(4):667-671.

31. Chibana K, et al. IL-13 induced increases in nitrite levels are primarily driven by increases in inducible nitric oxide synthase as compared with effects on arginases in human primary bronchial epithelial cells. Clin Exp Allergy. 2008;38(6):936-946.

32. Corren J, et al. Lebrikizumab treatment in adults with asthma. NEngl JMed. 2011;365(12):1088-1098.

33. Wenzel S, et al. Dupilumab in persistent asthma with elevated eosinophil levels. $N$ Engl J Med. 2013;368(26):2455-2466.

34. Wenzel S, Wilbraham D, Fuller R, Getz EB, Longphre M. Effect of an interleukin-4 variant on late phase asthmatic response to allergen challenge in asthmatic patients: results of two phase 2a studies. Lancet. 2007;370(9596):1422-1431.

35. Guo FH, et al. Interferon gamma and interleukin 4 stimulate prolonged expression of inducible nitric oxide synthase in human airway epithelium through synthesis of soluble mediators. JClin Invest. 1997;100(4):829-838.
36. Wenzel SE, Vitari CA, Shende M, Strollo DC, Larkin A, Yousem SA. Asthmatic granulomatosis: a novel disease with asthmatic and granulomatous features. Am J Respir Crit Care Med. 2012;186(6):501-507.

37. Mosmann TR, Cherwinski H, Bond MW, Giedlin MA, Coffman RL. Two types of murine helper T cell clone. I. Definition according to profiles of lymphokine activities and secreted proteins. J Immunol. 1986;136(7):2348-2357.

38. Robinson DS, et al. Predominant TH2-like bronchoalveolar T-lymphocyte population in atopic asthma. N Engl J Med.1992;326(5):298-304.

39. Broide DH, Paine MM, Firestein GS. Eosinophils express interleukin 5 and granulocyte macrophage-colony-stimulating factor mRNA at sites of allergic inflammation in asthmatics. JClin Invest. 1992;90(4):1414-1424.

40. Corrigan CJ, et al. CD4 T-lymphocyte activation in asthma is accompanied by increased serum concentrations of interleukin-5. Effect of glucocorticoid therapy. Am Rev Respir Dis. 1993;147(3):540-547.

41. Zhang DH, Cohn L, Ray P, Bottomly K, Ray A. Transcription factor GATA-3 is differentially expressed in murine Th1 and Th2 cells and controls Th2-specific expression of the interleukin-5 gene. J Biol Chem. 1997;272(34):21597-21603.

42. Zheng W, Flavell RA. The transcription factor GATA-3 is necessary and sufficient for Th2 cytokine gene expression in CD4 T cells. Cell. 1997;89(4):587-596.

43. Zhang DH, et al. Inhibition of allergic inflammation in a murine model of asthma by expression of a dominant-negative mutant of GATA-3. Immunity. 1999;11(4):473-482.

44. Nakamura Y, et al. Gene expression of the GATA-3 transcription factor is increased in atopic asthma. J Allergy Clin Immunol. 1999;103(2 Pt 1):215-222.

45. Zhu J, et al. Conditional deletion of Gata3 shows its essential function in $\mathrm{T}(\mathrm{H}) 1-\mathrm{T}(\mathrm{H}) 2$ responses. Nat Immunol. 2004;5(11):1157-1165.

46. Homburg U, et al. Safety and tolerability of a novel inhaled GATA3 mRNA targeting DNAzyme in patients with TH2-driven asthma. J Allergy Clin Immunol. 2015;136(3):797-800.

47. Krug N, et al. Allergen-induced asthmatic responses modified by a GATA3-specific DNAzyme. N Engl J Med. 2015;372(21):1987-1995.

48. Raundhal M, et al. High IFN- $\gamma$ and low SLPI mark severe asthma in mice and humans. JClin Invest. 2015;125(8):3037-3050.

49. Hanania NA, et al. Exploring the effects of omalizumab in allergic asthma: an analysis of biomarkers in the EXTRA study. Am J Respir Crit Care Med. 2013;187(8):804-811.

50. Flood-Page P, et al. A study to evaluate safety and efficacy of mepolizumab in patients with moderate persistent asthma. Am J Respir Crit Care Med. 2007;176(11):1062-1071.

51. Haldar P, et al. Mepolizumab and exacerbations of refractory eosinophilic asthma. N Engl J Med. 2009;360(10):973-984.

52. Pavord ID, et al. Mepolizumab for severe eosinophilic asthma (DREAM): a multicentre, double-blind, placebo-controlled trial. Lancet. 2012;380(9842):651-659.

53. Bel EH, et al. Oral glucocorticoid-sparing effect of mepolizumab in eosinophilic asthma. $N$ Engl J Med. 2014;371(13):1189-1197.

54. Nair P, et al. Mepolizumab for prednisone-dependent asthma with sputum eosinophilia. $N$ EnglJ Med. 2009;360(10):985-993.

55 . Ortega $\mathrm{H}$, et al. Mepolizumab treatment in patients with severe eosinophilic asthma. $N$ Engl J Med. 2014;371(13):1198-1207.

56. Castro M, et al. Reslizumab for poorly controlled, eosinophilic asthma: a randomized, placebocontrolled study. Am J Respir Crit Care Med. 2011;184(10):1125-1132.

57. Castro M, et al. Benralizumab, an anti-interleukin 5 receptor $\alpha$ monoclonal antibody, versus placebo for uncontrolled eosinophilic asthma: a phase $2 \mathrm{~b}$ randomised dose-ranging study. Lancet Respir Med. 2014;2(11):879-890.

58. Piper E, et al. A phase II placebo-controlled study of tralokinumab in moderate-to-severe asthma. Eur Respir J. 2013;41(2):330-338.

59. Barnes N, et al. A randomized, double-blind, placebo-controlled study of the CRTH2 antagonist OC000459 in moderate persistent asthma. Clin Exp Allergy. 2012;42(1):38-48.

60. Pettipher R, et al. Heightened response of eosinophilic asthmatic patients to the CRTH2 antagonist OC000459. Allergy. 2014;69(9):1223-1232.

61. Erpenbeck VJ, et al. QAW309 (fevipirant) improves lung function and control of asthma symptoms in patients with more severe air flow limitation: a proof-of-concept study. Eur Respir J. 2015;46(suppl 59). http://dx.doi. org/10.1183/13993003.congress-2015.PA2125. Accessed May 13, 2016.

62. Gauvreau GM, et al. Effects of an anti-TSLP antibody on allergen-induced asthmatic responses. N Engl JMed. 2014;370(22):2102-2110.

63. Castro M, et al. Reslizumab for inadequately controlled asthma with elevated blood eosinophil counts: results from two multicentre, parallel, double-blind, randomised, placebo-controlled, phase 3 trials. Lancet Respir Med. 2015;3(5):355-366.

64. Bachert C, et al. Effect of subcutaneous dupilumab on nasal polyp burden in patients with chronic sinusitis and nasal polyposis: a randomized clinical trial. JAMA. 2016;315(5):469-479.

65. Holtzman MJ, Byers DE, Alexander-Brett J, Wang $\mathrm{X}$. The role of airway epithelial cells and innate immune cells in chronic respiratory disease. Nat Rev Immunol. 2014;14(10):686-698.

66. Bernink JH, Germar K, Spits H. The role of ILC2 in pathology of type 2 inflammatory diseases. Curr Opin Immunol. 2014;31:115-120.

67. Martinez-Gonzalez I, Steer CA, Takei F. Lung ILC2s link innate and adaptive responses in allergic inflammation. Trends Immunol. 2015;36(3):189-195.

68. Hoyler T, et al. The transcription factor GATA-3 controls cell fate and maintenance of type 2 innate lymphoid cells. Immunity. 2012;37(4):634-648.

69. Tindemans I, Serafini N, Di Santo JP, Hendriks RW. GATA-3 function in innate and adaptive immunity. Immunity. 2014;41(2):191-206.

70. Lloyd CM, Saglani S. Epithelial cytokines and pulmonary allergic inflammation. Curr Opin Immunol. 2015;34:52-58.

71. Chang JE, Doherty TA, Baum R, Broide D. Pros- 
taglandin D2 regulates human type 2 innate lymphoid cell chemotaxis. J Allergy Clin Immunol. 2014;133(3):899-901.e3.

72. Xue L, et al. Prostaglandin D2 activates group 2 innate lymphoid cells through chemoattractant receptor-homologous molecule expressed on TH2 cells. J Allergy Clin Immunol. 2014;133(4):1184-1194.

73. Halim TY, Krauss RH, Sun AC, Takei F. Lung natural helper cells are a critical source of Th2 cell-type cytokines in protease allergen-induced airway inflammation. Immunity. 2012;36(3):451-463.

74. Chustz RT, et al. Regulation and function of the IL-1 family cytokine IL-1F9 in human bronchial epithelial cells. Am J Respir Cell Mol Biol. 2011;45(1):145-153.

75. Hsu J, Lanza DC, Kennedy DW. Antimicrobial resistance in bacterial chronic sinusitis. Am J Rhinol. 1998;12(4):243-248.

76. Aizenbud D, et al. Alveolar ridge notching as a predictor for secondary bone grafting in incomplete alveolar clefts. Cleft Palate Craniofac J. 2004;41(5):575-576.

77. Afonina IS, Müller C, Martin SJ, Beyaert R. Proteolytic processing of interleukin-1 family cytokines: variations on a common theme. Immunity. 2015;42(6):991-1004.

78. Jackson DJ, et al. IL-33-dependent type 2 inflammation during rhinovirus-induced asthma exacerbations in vivo. Am J Respir Crit Care Med. 2014;190(12):1373-1382.

79. Saglani S, et al. IL-33 promotes airway remodeling in pediatric patients with severe steroidresistant asthma. JAllergy Clin Immunol. 2013;132(3):676-685.e13.

80. Nagakumar P, Denney L, Fleming L, Bush A, Lloyd CM, Saglani S. Type 2 innate lymphoid cells in induced sputum from children with severe asthma. JAllergy Clin Immunol. 2016;137(2):624-626.e6.

81. Smith SG, et al. Increased numbers of activated group 2 innate lymphoid cells in the airways of patients with severe asthma and persistent airway eosinophilia. J Allergy Clin Immunol. 2016;137(1):75-86.e8.

82. Shaaban R, et al. Rhinitis and onset of asthma: a longitudinal population-based study. Lancet. 2008;372(9643):1049-1057.

83. ten Brinke A, Zwinderman AH, Sterk PJ, Rabe KF, Bel EH. Factors associated with persistent airflow limitation in severe asthma. Am J Respir Crit Care Med. 2001;164(5):744-748.

84. Stirling RG, van Rensen EL, Barnes PJ, Chung KF. Interleukin-5 induces CD34(+) eosinophil progenitor mobilization and eosinophil CCR3 expression in asthma. Am J Respir Crit Care Med. 2001;164(8 Pt 1):1403-1409.

85. Wang J, et al. Circulating, but not local lung, IL-5 is required for the development of antigeninduced airways eosinophilia. JClin Invest. 1998;102(6):1132-1141.

86. Wenzel SE, et al. Evidence that severe asthma can be divided pathologically into two inflammatory subtypes with distinct physiologic and clinical characteristics. Am J Respir Crit Care Med.
1999;160(3):1001-1008.

87. Wenzel SE, Szefler SJ, Leung DY, Sloan SI, Rex MD, Martin RJ. Bronchoscopic evaluation of severe asthma. Persistent inflammation associated with high dose glucocorticoids. Am J Respir Crit Care Med. 1997;156(3 Pt 1):737-743.

88. Ordoñez CL, Shaughnessy TE, Matthay MA, Fahy JV. Increased neutrophil numbers and IL-8 levels in airway secretions in acute severe asthma: clinical and biologic significance. Am J Respir Crit Care Med. 2000;161(4 Pt 1):1185-1190.

89. Shannon J, et al. Differences in airway cytokine profile in severe asthma compared to moderate asthma. Chest. 2008;133(2):420-426.

90. Truyen E, et al. Evaluation of airway inflammation by quantitative Th1/Th2 cytokine mRNA measurement in sputum of asthma patients. Thorax. 2006;61(3):202-208.

91. Li X, et al. Genome-wide association study identifies TH1 pathway genes associated with lung function in asthmatic patients. J Allergy Clin Immunol. 2013;132(2):313-20.e15.

92. Dahlberg PE, Busse WW. Is intrinsic asthma synonymous with infection? Clin Exp Allergy. 2009;39(9):1324-1329.

93. Ryjenkov DA, Tarutina M, Moskvin OV, Gomelsky M. Cyclic diguanylate is a ubiquitous signaling molecule in bacteria: insights into biochemistry of the GGDEF protein domain. JBacteriol. 2005;187(5):1792-1798.

94. Burdette DL, et al. STING is a direct innate immune sensor of cyclic di-GMP. Nature. 2011;478(7370):515-518.

95. Ebensen T, Schulze K, Riese P, Link C, Morr M, Guzman CA. The bacterial second messenger cyclic diGMP exhibits potent adjuvant properties. Vaccine. 2007;25(8):1464-1469.

96. Hayashi N, Yoshimoto T, Izuhara K, Matsui K, Tanaka T, Nakanishi K. T helper 1 cells stimulated with ovalbumin and IL-18 induce airway hyperresponsiveness and lung fibrosis by IFNgamma and IL-13 production. Proc Natl Acad Sci U S A. 2007;104(37):14765-14770.

97. Yang M, Kumar RK, Foster PS. Pathogenesis of steroid-resistant airway hyperresponsiveness: interaction between IFN-gamma and TLR4/MyD88 pathways. JImmunol. 2009;182(8):5107-5115.

98. Laan M, et al. Neutrophil recruitment by human IL-17 via C-X-C chemokine release in the airways. JImmunol. 1999;162(4):2347-2352.

99. Bullens DM, et al. IL-17 mRNA in sputum of asthmatic patients: linking $\mathrm{T}$ cell driven inflammation and granulocytic influx? Respir Res. 2006;7:135.

100.Liang SC, et al. An IL-17F/A heterodimer protein is produced by mouse Th17 cells and induces airway neutrophil recruitment. J Immunol. 2007;179(11):7791-7799.

101. McKinley L, et al. TH17 cells mediate steroidresistant airway inflammation and airway hyperresponsiveness in mice. JImmunol. 2008;181(6):4089-4097.

102. Busse WW, et al. Randomized, double-blind, placebo-controlled study of brodalumab, a human anti-IL-17 receptor monoclonal antibody, in moderate to severe asthma. Am J Respir Crit Care Med. 2013;188(11):1294-1302.

103. Codarri L, et al. ROR $\gamma$ t drives production of the cytokine GM-CSF in helper T cells, which is essential for the effector phase of autoimmune neuroinflammation. Nat Immunol. 2011;12(6):560-567.

104.El-Behi M, et al. The encephalitogenicity of $\mathrm{T}(\mathrm{H}) 17$ cells is dependent on IL-1- and IL-23-induced production of the cytokine GM-CSF. Nat Immunol. 2011;12(6):568-575.

105. Ghoreschi K, et al. Generation of pathogenic $\mathrm{T}(\mathrm{H}) 17$ cells in the absence of TGF- $\beta$ signalling. Nature. 2010;467(7318):967-971.

106.Zabieglo K, et al. The inhibitory effect of secretory leukocyte protease inhibitor (SLPI) on formation of neutrophil extracellular traps. J Leukoc Biol. 2015;98(1):99-106.

107. Jin FY, Nathan C, Radzioch D, Ding A. Secretory leukocyte protease inhibitor: a macrophage product induced by and antagonistic to bacteria lipopolysaccharide. Cell. 1997;88(3):417-426.

108. Barrios VE, Jarosinski MA, Wright CD. Proteinase-activated receptor-2 mediates hyperresponsiveness in isolated guinea pig bronchi. Biochem Pharmacol. 2003;66(3):519-525.

109. Tam EK, Caughey GH. Degradation of airway neuropeptides by human lung tryptase. Am J Respir Cell Mol Biol. 1990;3(1):27-32.

110.Yu M, et al. Identification of an IFN- $\gamma /$ mast cell axis in a mouse model of chronic asthma. JClin Invest. 2011;121(8):3133-3143.

111. Ashcroft GS, et al. Secretory leukocyte protease inhibitor mediates non-redundant functions necessary for normal wound healing. Nat Med. 2000;6(10):1147-1153.

112. Makinde T, Murphy RF, Agrawal DK. The regulatory role of TGF-beta in airway remodeling in asthma. Immunol Cell Biol. 2007;85(5):348-356.

113. Cockcroft DW, Davis BE. Airway hyperresponsiveness as a determinant of the early asthmatic response to inhaled allergen. J Asthma. 2006;43(3):175-178.

114. Voraphani N, et al. An airway epithelial iNOSDUOX2-thyroid peroxidase metabolome drives Th1/Th2 nitrative stress in human severe asthma. Mucosal Immunol. 2014;7(5):1175-1185.

115. Sampath D, Castro M, Look DC, Holtzman MJ. Constitutive activation of an epithelial signal transducer and activator of transcription (STAT) pathway in asthma. JClin Invest. 1999;103(9):1353-1361.

116. Lazear HM, et al. Interferon- $\lambda$ restricts West Nile virus neuroinvasion by tightening the bloodbrain barrier [published erratum appears in $\mathrm{Sci}$ Transl Med. 2015;7(289):289er5]. Sci Transl Med. 2015;7(284):284ra59.

117. Zhang Y, et al. PARP9-DTX3L ubiquitin ligase targets host histone $\mathrm{H} 2 \mathrm{BJ}$ and viral $3 \mathrm{C}$ protease to enhance interferon signaling and control viral infection. Nat Immunol. 2015;16(12):1215-1227.

118. Reddy AP, Gupta MR. Management of asthma: the current US and European guidelines. Adv Exp Med Biol. 2014;795:81-103. 